\section{Time signatures}

\author{
Douglas Palmer
}

Terrestrial Ecosystems Through Time: Evolutionary Paleoecology of Terrestrial Plants and Animals. Edited by $A$. K. Behrensmeyer, J. D. Damuth, W. A. DiMichele, R. Potts, H.-D. Sues and S. L. Wing. University of Chicago Press: 1992. Pp. 568. £59.95, \$75 (hbk); $£ 23.95, \$ 29.95$ (pbk).

THIS ambitious book represents the first attempt in print to discuss comprehensively the evolution of terrestrial ecosystems from Ordovician times, some 500 million years ago, through to the postPleistocene and the effects of humans. But it is much more than that: the first four chapters (roughly two hundred pages) are devoted to the methods of evolutionary palaeoecology, analysis of palaeoenvironments in general, taphonomic modes and a discussion of how extinct organisms can be characterized ecologically. In other words, the authors have gone to a great deal of trouble to define their terms and establish the ground rules for this new area. Justifiably so, because the project cuts across many interdisciplinary boundaries and involves a huge diversity of data and new information.

The book grew out of the first Evolution of Terrestrial Ecosystems Conference held near Washington DC in 1987. It is a carefully reworked synthesis of palaeoecological data and ideas set within the framework of geological time, presented by more than 30 invited contributors. And herein lies a fundamental methodological problem for palaeoecology: namely, the resolution of geological time. At best, Palaeozoic time cannot yet be resolved finer than 1 million years and even when we are dealing with the relatively recent past, for example the Pliocene (1.64-5.2 million years ago), the temporal resolution and correlation of strata between localities cannot generally be refined to within anything like the generational lifespans of ecology.

As Richard Potts and his coauthors of Chapter 7 on Late Cenozoic terrestrial ecosystems write: "much of the significant work in paleoecology depends upon temporal correlations, from which processes or causes of ecological change may be inferred". Even in the "most recent' geological past such as the late Pleistocene (within the spectrum of carbon-14 dating), there are interesting and important questions about the role of humans in the megafaunal extinctions, when roughly 200 genera of large mammals disappeared within a few thousand years. To what extent can palaeoecology help to provide answers?
If the problems of temporal resolution and correlation can be overcome, then the study of evolutionary palaeoecology will benefit enormously. It will become an important tool that will help us to understand even better the immediate impact and long-term effects of human activity on Earth's ecosystems. Today, more than ten per cent of the total land on Earth is farmed, producing a dramatic change in the structures and dynamics of the global ecosystem, on a scale that is to be found only in the distant past. Suddenly, the major ecosystem changes of the Palaeozoic and Mesozoic take on a new relevance.

The authors do not try to duck the problems of temporal scaling, but use them to encourage future work with "carefully reconstructed local sequences of biotic, climatic, and geologic history" that are essential to understand "the behaviour of ecological systems over macroevolutionary time". This novel approach will hopefully provide a new impetus to the study of the geological history of Earth and its biota. This stimulating book deserves to be read well beyond the confines of the palaeontological community, as the themes that it addresses are important for us all. But to what extent we can learn to modify our future behaviour as a result of understanding the past remains to be seen.

Douglas Palmer is at 31 Mawson Road, Cambridge $\mathrm{CBI} 2 \mathrm{OZ}$, UK.

\section{Selective attention}

\section{Steven Rose}

Bright Air, Brilliant Fire: On the Matter of the Mind. By Gerald Edelman. Basic Books/Allen Lane: 1992. Pp.280. \$25. $£ 20$.

Gerald Edelman works on a broad canvas. His three earlier books, Neural Darwinism, Topobiology and The Remembered Present, published in rapid succession, offered nothing less than comprehensive theories of memory, development and the evolution of mind and of consciousness. His new book is intended as a somewhat more accessibly written résumé of the earlier three and as a challenge to many previous philosophies of mind. Edelman's theory has attracted both loyal support and strong opposition: the neurologist Oliver Sacks finds it inspirational; the molecular biologist Francis Crick, not averse to his own speculative flings on similar themes, has somewhat dismissively dubbed it
"Neural Edelmanism". Reviewers of the three earlier books in Nature were similarly divided (see Nature 331, 571, 1988; 336, 272, 1988; 343, 603, 1990).

As is now well known, Edelman's approach, which he categorizes as evolutionary and bases on darwinian principles, depends on what he abbreviates to TNGS, a "theory of neuronal group selection". TNGS holds that the fine details of the connectivity of the brain depend on the competitive selection of neurons and synapses during development, this selection occurring at the level of neuronal groups rather than individual cells and being driven by the pruning force of experiential contingency on the initial efflorescence of neuronal processes occurring early in the development of the vertebrate central nervous system. In these modest terms, such a model is uncontroversial. Developmental pruning and stabilization of synapses have been demonstrated and speculated about by Edelman and others, such as J.-P. Changeux, since the mid-1970s. The molecular mechanism Edelman proposes for this stabilization involves a class of glycoprotein cell adhesion molecules (N-CAMs), the discovery of which he himself was closely involved with; although in his books he simplifies their role (there are many other classes of molecule - such as the integrins involved in synaptic recognition and stabilization), there is no doubt of the relevance of these molecules. Several research groups have recently demonstrated the involvement of the N-CAMs in the formation of memory.

But a theory of consciousness, or even of memory, requires more than molecular mechanisms, and to them Edelman adds an emphasis on what he calls the "reentrant" behaviour of neural circuitry - by which I assume he means, for it is nowhere defined in any of the books, the multiple feedback and feedforward loops through which groups of neurons are linked in space and time with their capacity for dynamic, plastic reorganization. Armed with this model, Edelman takes several fashionable theories of brain function, including, above all, the enthusiasm for "computational neuroscience" among neural-network modellers. The brain is not a computer, he reminds us often, forcibly and justifiably - a welcome emphasis, though he weakens the argument by then presenting his own learning robot with an inbuilt computer, called, in deference to his theoretical predilections, Darwin III. It is difficult for the uninitiated to appreciate from the account given in this book just how Darwin III's approach to learning differs from that of the modellers of whom Edelman disapproves.

TNGS contrasts Edelman's "selectionist" metaphor of neural development 